\title{
LA INVENCIÓN DE UNA PROMESA: \\ NOSTALGIA COLONIAL Y JERARQUÍA RACIAL EN DOÑA INÉS CONTRA EL OLVIDO DE ANA TERESA TORRES
}

\author{
POR \\ Patricia Valladares-Ruiz \\ University of Cincinnati
}

Non que ce monde ancien et passé bougeât! Ce monde ne se reтие plus. On le reтие.

Michel de Certeau

Desde la novela del xix hasta el tratamiento posmoderno de la nueva novela histórica de finales del siglo xx, la representación literaria de personajes afrovenezolanos ha sido mayoritariamente articulada por escritores blancos para lectores blancos. No pocos han sido los casos en los que estos textos se han alimentado del sistema colonial de jerarquías del color y lo han reproducido. En estas narrativas proliferan procesos de racialización que raras veces logran tambalear las tradicionales representaciones de personajes negros construidos en oposición al de su equivalente blanco, donde el primero está destinado a ocupar el espacio subalterno del binomio.

La representación de sujetos afrodescendientes en la narrativa venezolana ha tendido a articularse en torno a tres ejes temáticos bastante bien definidos. El primero de ellos recoge las narraciones de corte histórico, tales como ¡En este país! (1916) de Luis Urbaneja Achelpohl, Peregrina o El pozo encantado (1922) de Manuel Díaz Rodríguez, Pobre negro (1937) de Rómulo Gallegos, Las lanzas coloradas (1931) de Arturo Úslar Pietri y, entre otros ejemplos, Boves, el urogallo (1972) de Francisco Herrera Luque. En estos textos, las acciones de los personajes negros - casi en su totalidad hombres-a menudo están vinculadas a su participación en la gesta independentista y en la Guerra Federal. La incorporación de estos personajes alimentaría la retórica integracionista que postulaba la participación de todos los grupos raciales (blancos, negros, indígenas y mestizos) en el proyecto de construcción nacional; de esta forma, estas narrativas habrían contribuido a la propagación del mito de la convivencia armoniosa de las razas. Un segundo grupo reuniría textos de temática rural cuyas acciones se desarrollan en haciendas cafetaleras, conucos, campos petroleros y comunidades de negros asentadas en las zonas costeras. Tales son los casos de Peonía (1890) de Manuel Vicente Romero García, Mene (1936) y Borburata (1960) de Ramón Díaz Sánchez, Los conuqueros (1936) de Julio Ramos y Nochebuena negra (1943) de Juan Pablo Sojo. Un último conjunto 
agruparía las narrativas urbanas en torno a la inmigración de sujetos afrodescendientes de las zonas rurales a las ciudades, como lo son las novelas de Guillermo Meneses, Canción de negros (1934) y Campeones (1939).

En este brevísimo e incompleto recorrido por la representación de personajes negros en la narrativa venezolana son recurrentes los usos de ciertos registros lingüísticos y estereotipos sociales y culturales que, en lugar de celebrar la diversidad racial de la sociedad venezolana, favorecerían la perpetuación de la blancura como modelo hegemónico a alcanzar. En suma, muchos de estos textos proponen una mirada exotizante y telescópica que se encargaría de relegar a estos sujetos a los márgenes y excluirlos del concierto nacional, al tiempo que resguardaría la preeminencia de la blancura racial y cultural Esto es posible apreciarlo en novelas como Pobre negro y Las lanzas coloradas en las que los personajes negros son delineados a partir de dicotomías sustentadas en la supremacía del hombre blanco, cristiano, burgués, urbano y educado. Por tanto, poco sorprenderá que -en el inventario de silencios y ausencias que definen la representación literaria de la afrovenezolanidad- descuelle la escasa representación de personajes de mujeres negras que logren escapar del cumplimiento una mera función ornamental y que ocupen espacios protagónicos en estas narraciones.

En las narrativas de corte histórico producidas en las últimas dos décadas, destaca la novela Doña Inés contra el olvido (1992) de Ana Teresa Torres, una de las escritoras más celebradas en el panorama literario venezolano contemporáneo. En su acercamiento a esta novela, buena parte de la crítica ha privilegiado la lectura de los referentes históricos, el cuestionamiento literario de la historia oficial, la óptica femenina del discurso intrahistórico y, entre otros aspectos temáticos, la reescritura del pasado colonial desde una perspectiva nostálgica. La lectura que aquí presento de Doña Inés contra el olvido persigue el examen detenido de la representación de personajes afrodescendientes y, más precisamente, de cómo estos personajes permiten cuestionar el vínculo significativo entre la historia de doña Inés y sus antecedentes discursivos. En el nivel intradiegético estos antecedentes apuntarían a la historia oficial contra la que doña Inés se enfrenta por medio de su testimonio; mientras que en el nivel extradiegético, la novela de Torres se rebelaría-por medio del artificio paródico-en contra de una tradición literaria de novelas históricas que justificaban el proceso de construcción nacional con la reproducción del mito de la convivencia armoniosa entre los grupos raciales.

El estudio de los mecanismos de representación de sujetos afrodescendientes requiere de una reflexión acerca de las tensiones raciales y sociales que tambalean, por adhesión u oposición, los discursos hegemónicos sobre la identidad nacional venezolana. Asimismo, el análisis de la dinámica paródica en esta novela propicia una reflexión sobre el papel que juegan los personajes afrovenezolanos en la ficcionalización de eventos históricos (desde el periodo colonial hasta finales del siglo xx) representados en esta novela. En esta línea, me intereso en los fenómenos de continuidad y ruptura en la inscripción de

Revista Iberoamericana, Vol. LXXIX, Núms. 244-245, Julio-Diciembre 2013, 1103-112 ISSN 0034-9631 (Impreso) ISSN 2154-4794 (Electrónico) estereotipos asociados a las subjetividades afrodescendientes y, más particularmente, en cómo contribuyen estos personajes a construir un espacio discursivo alternativo.

Tanto en su ataque al discurso historiográfico oficial como en su exaltación de la memoria histórica, esta novela trazaría, desde la ficción, una genealogía de los conflictos entre grupos raciales y sociales surgidos al fragor de la maquina esclavista y cuyos ecos aún resuenan en la actualidad. Desde esta perspectiva, la lectura de Doña Inés contra el olvido revela una clara afinidad con otras narrativas históricas del descalabro, entre las que podemos mencionar novelas como: Memorias de un venezolano de la decadencia (José Rafael Pocaterra, 1936), Fiebre (Miguel Otero Silva, 1939), Jabón de olor (Gerónimo Pérez Rescaniere, 1973), La isla de Róbinson (Arturo Uslar Pietri, 1981), La última cena (Stefanía Mosca 1990); e incluso textos posteriores como Los amos del valle (Francisco Herrera Luque, 1993) y Rocanegras (Fedosy Santaella, 2007). Estas novelas coincidirían con Doña Inés contra el olvido en sus acercamientos a eventos y periodos históricos que apuntarían al fracaso de un proyecto nacional afianzado sobre ideales de concordia (racial y social) y de progreso, donde la búsqueda del bien común (la patria) se resquebraja como consecuencia de la prevalencia del personalismo, caudillismo y sectarismo a través de más de dos siglos.

En este empresa es importante considerar la recreación literaria de la relación entre memoria y temporalidad. En sus reflexiones en torno a la recuperación del pasado a través de la memoria, Andreas Huyssen advierte que la renovada obsesión con la historia no es el resultado de un síndrome finisecular posmoderno; al contrario, es un signo de la crisis de la ideología de progreso y la modernización y, por otra parte, de la estructura de temporalidad que marcó la era moderna con la celebración de lo nuevo como utópico, como radical e irreductiblemente Otro (6). En este sentido, el ejercicio narrativo de Torres recrearía la arbitrariedad que supone el ordenamiento de eventos históricos recogidos por la memoria individual y colectiva. En el caso que ocupa nuestra atención, estos eventos responderían no sólo a los intereses personales de la narradora, doña Inés, sino también a los que su condición de mujer blanca y mantuana impone. Desde luego, estos rasgos la distanciarían de anteriores narrativas de corte histórico tradicionalmente articuladas desde la perspectiva masculina. En la novela de Torres, el examen del pasado familiar y nacional cumpliría con dos propósitos en apariencia contradictorios. En un primer nivel de enunciación, la narración de la historia de los Villegas y Solórzano que nos presenta doña Inés respondería a su afán de añoranza de un periodo colonial en el que su familia vivía apaciblemente y gozaba de prestigio social. En este sentido, la obsesión de doña Inés con la historia familiar respondería a una necesidad de redisponer unos eventos cuyo orden original habría sido alterado por el abuso de poder de grupos políticos dominantes a lo largo de más de dos siglos. ${ }^{1}$ Sin embargo, en un segundo

En su estudio sobre la metaficción historiográfica, Santiago Juan-Navarro enfatiza el cuestionamiento del discurso histórico en la novela posmoderna: "La historia no es concebida como un ámbito objetivo que

Revista Iberoamericana, Vol. LXXIX, Núms. 244-245, Julio-Diciembre 2013, 1103-1121 ISSN 0034-9631 (Impreso) ISSN 2154-4794 (Electrónico) 
nivel de enunciación, el ejercicio de esta "nostalgia restauradora" abriría paso, por una parte, a una crítica incisiva -a través de la recreación paródica de discursos adscritos a la historia oficial- de un proyecto nacional que pretendió reproducir y prolongar las relaciones jerárquicas de raza, género y clase que engrasaron la máquina colonial. De esta forma, el testimonio transhistórico de doña Inés transitaría un espacio liminal entre el malestar mantuano ${ }^{2}$ y la revancha de los desclasados.

\section{De LA SIESTA COLONIAL A LA ALGARABÍA EMANCIPADORA}

Desde el punto de vista estructural, Doña Inés contra el olvido está dividida en tres partes; cada una de ellas se ocupa de distintos periodos políticos de la historia venezolana: $1715-1835,1846-1935$ y 1935-1985. En el transcurso de estos periodos, la narradora, doña Inés Villegas y Solórzano, un ama de casa mantuana, rememora el curso de un largo litigio por unas tierras cacaoteras de Curiepe (costa central de Venezuela) Durante los últimos años de su vida e incluso después de su muerte, doña Inés indaga en los eventos que giraron en torno a la sucesión de las tierras, la búsqueda de títulos de propiedad y los procesos políticos que afectaron directamente el destino de aquellas tierras. En el siglo xVIII, etapa inicial de esta historia, la explotación y exportación de cacao venezolano estaba en pleno auge. Los dueños de haciendas cacaoteras no sólo ostentaban una situación económica muy privilegiada, sino que también contaban con acceso a las altas esferas del poder político local.

La voz espectral de doña Inés modela un recorrido por la historia venezolana, desde su condición de mujer blanca, perteneciente a la clase social más pudiente en la Venezuela colonial. A pesar de encontrarse en una situación aparentemente privilegiada, la misma sociedad que protege su estatus social, la condena a un espacio subalterno debido a su género. De este modo, al contar la historia de sus tierras, de su familia y de Venezuela, doña Inés transgrede el orden colonial. Como se expone en la primera parte de la novela, doña Inés, aunque capacitada para imponer su voluntad sobre el

pueda ser 'encapsulado' dentro de un discurso puramente denotativo, sino como un discurso problemático y fluctuante que reflexiona sobre el pasado desde el presente ideológicamente condicionado del escritor Este replanteamiento de la naturaleza y funciones del discurso histórico no se limita a cuestionar los principios legitimeres de la verdad histórica oficial, sino que puede llegar a tener además un varor (235). Desde esta perpectiva, la un valor pache de Torres atacaria las formas discursivas dom de voces periféricas y previamente relegadas.

Por su parte, Ángel Rosenblat define este grupo como: “[L]os criollos nobles de Caracas, que habían apoyado -con las debidas precauciones- el movimiento de Juan Francisco de León contra la Compañía Guipuzcoana, y lo abandonaron totalmente en el momento de la represión. Eran los dueños de las haciendas ("la oligarquía territorial", dice Gil Fortoul), afectados por el monopolio vizcaíno" (64-65). ISSN 0034-9631 (Impreso)

Vol. LXXIX, Núms. 244-245, Julio-Diciembre 2013, 1103-112 ISSN 2154-4794 (Electrónico) grupo de esclavos a su servicio, no alcanza a gozar de ciertos privilegios exclusivos de los hombres mantuanos. Entre alguna de estas prerrogativas se pueden mencionar el acceso a la educación, la participación en negocios y en la vida política local y, entre otros, la posibilidad de erigirse como voces y plumas autorizadas.

Como se puede apreciar en la novela, la narradora recrea un diálogo imaginario con otros personajes envueltos en el litigio. Más precisamente, se trata de un monólogo que sugiere la puesta en escena de un diálogo; pues, aunque doña Inés se dirija a sus interlocutores, estos nunca alcanzan a darle la réplica. Estos interlocutores son su esposo, Alejandro Martínez de Villegas y Blanco, y su paje y liberto, Juan del Rosario (hijo ilegítimo de su esposo y una de las esclavas de la hacienda). Doña Inés también dirige sus reclamos a otras figuras públicas como reyes (Carlos III y Carlos IV), presidentes, gobernadores, alcaldes y escribanos. Si bien lecturas críticas como la de Fabiola Franco han rescatado el carácter polifónico de esta novela (71), en rigor, estaríamos ante una mirada única sobre un reportorio de personajes variopintos, distanciados entre sí por el sexo, la clase social, la raza, la religión, el origen nacional y el contexto histórico.

Como he mencionado anteriormente, la visión de la historia que prevalece a lo largo de la novela es la de doña Inés. En esta línea conviene tener en cuenta las referencias de la propia narradora a su sordera, un mal que achaca a su avanzada edad. En un plano simbólico, esta condición también respondería a su desinterés por todo aquello que no afecte directamente el mencionado litigio. De ahí también se desprende su insistencia en "componer su historia" (13); una que dista mucho de ser la historia de los hombres mantuanos, esclavos, campesinos, cronistas y estadistas. A través del escrutinio de pequeños eventos cotidianos, la narradora examina los grandes procesos históricos. Los litigios familiares serían un eco metafórico de las disputas que marcaron el periodo colonial, la emancipación, la república y los regímenes dictatoriales y democráticos del siglo XX.

Con esta novela, Torres contribuye al creciente corpus de narrativas venezolanas contemporáneas de temática histórica. ${ }^{4}$ María Bruña Bragado relaciona este ataque a la "versión oficial" de la historia a cierto descontento por el descalabro político y económico de las últimas décadas del siglo xx (195). ${ }^{5}$ En esta línea, Doña Inés contra el olvido plantearía, entonces, el reflejo inverso de las narrativas de finales del xIX y de

\footnotetext{
A propósito de la reescritura de la historia a partir del recuento de eventos cotidianos, conviene consultar el estudio de Luz Marina Rivas sobre la novela venezolana intrahistórica (2004).

Varias de estas narrativas han sido producidas por mujeres escritoras, como son los casos de Antonieta Madrid, Victoria de Stefano, Laura Antillano y Milagros Mata Gil (Bruña 195).

Uno de los síntomas más dramáticos de este periodo se reflejaría en el llamado Caracazo, una serie de protestas y disturbios en contra de un paquete de medidas económicas neoliberales impuesto por gobierno de Carlos Andrés Pérez. Este movimiento popular tuvo lugar entre el 27 y 28 de febrero de y culminó con una matanza a cargo de las fuerzas de seguridad del Estado.
} 
la primera mitad del $\mathrm{xx}$ en torno a las relaciones entre los diferentes grupos sociales $\mathrm{y}$ raciales que participaron en el proyecto de construcción nacional.

En anteriores narrativas sobre las guerras del XIX, los conflictos sociales se asociaban a las jerarquías raciales impuestas por el sistema colonial y que habrían de ser superadas, al menos en apariencia, tras el triunfo de la gesta independentista. Sin embargo, Doña Inés contra el olvido, en tanto que novela histórica posmoderna, reacciona en contra de una historia oficial de vocación integradora para denunciar las tensiones aún no superadas entre los grupos antagónicos; tal como lo podemos apreciar en la última parte del texto, que se ocupa del periodo comprendido entre 1935 y 1985. Si bien la novela de Torres se alimenta del modelo tradicional de la novela histórica, no sólo no participa de la representación idealizada de la gran familia nacional, sino que confronta y contradice esta postura. Precisamente, Doña Inés contra el olvido se sirve de ese modelo para desmontarlo por medio del artificio paródico y exponer el mecanismo de perpetuación de la supremacía mantuana en la sociedad venezolana.

Es crucial tener en cuenta que la narradora, distanciándose de la tradición literaria de tema histórico, no ofrece un acercamiento empático, compasivo ni mucho menos redentor sobre los colectivos que tradicionalmente han sido victimizados o ensalzados en el marco de la representación literaria del periodo independentista. En su impulso satírico, el texto de Torres nos presenta a una mantuana que se percibe como damnificada del trance político que le arrebatara sus tierras cacaoteras. En consecuencia, en Doña Inés contra el olvido impera la representación de sujetos esclavos y descendientes desde una perspectiva que, además de condenarlos a un espacio subalterno, los identifica como elementos nocivos del orden colonial, de la bonanza económica y del poder político y social de los blancos criollos.

Ningún personaje resulta indemne del ajuste de cuentas de doña Inés, ni las fuerzas realistas ni las republicanas. En este panorama, los personajes afrodescendientes ya no son representados exclusivamente como víctimas de la empresa esclavista o como soldados aguerridos y fieles a los próceres blancos de la Independencia. El tono despectivo de muchos de los ataques de doña Inés en contra de estos personajes respondería a la voz de una mujer de su tiempo y su condición. La representación burlona de las clases dominantes revelaría la falsedad de los discursos integracionistas del XIX, que elogiaban

Desde esta perspectiva la novela de Torres desarmaría las retóricas integracionistas que podemos identificar en novelas canónicas como las de Eduardo Blanco (1881), Luis Manuel Urbaneja Achelpoh (1916) y Arturo Úslar Pietri (1931). Para un análisis exhaustivo de las relaciones entre la emergencia del sujeto nacional y la articulación de identidades sexuales y raciales en la narrativa latinoamericana, conviene revisar el conocido ensayo de Doris Sommer, Foundational Fictions (1991).

$\mathrm{Al}$ respecto, resulta particularmente útil la caracterización del potencial crítico del texto paródico que propone Linda Hutcheon: “Parody, then in its ironic 'trans-conceptualization' and inversion, is repetition with difference. A critical distance is implied between the backgrounded text being parodied and the new incorporated work, a distance usually signaled by irony" (32)

17.7 Revista Iberoamericana, Vol. LXXIX, Núms. 244-245, Julio-Diciembre 2013, 1103-1121 ISSN 0034-9631 (Impreso) ISSN 2154-4794 (Electrónico) la participación de todos los grupos sociales y raciales a favor de la construcción de la nación. En contrapartida, la historia patria que nos ofrece doña Inés está cubierta con un manto de desencanto. El origen de la frustración de la narradora se sitúa en el periodo colonial, cuando los mantuanos -a pesar de sentirse los legítimos propietarios del territorio que habitaban- debían someterse a los designios del aparato imperial. Superado el periodo que la narradora definiera como la "siesta colonial" y tras el tránsito fragoso por las guerras del XIX, la aristocracia criolla tuvo que enfrentarse a la emergencia de otros factores sociales con los cuales debía pactar la repartición de nuevos poderes políticos, sociales y económicos. La historia de doña Inés es una de desencuentros y, sobre todo, de enfrentamientos con un Otro que, en el caso de la protagonista, puede ser cualquiera que obstaculice la perpetuación de la supremacía mantuana.

En su condición de testigo espectral y omnipresente, doña Inés es testigo y cronista de una serie de cambios políticos y socioeconómicos que la llevan a asegurar que su vida, sus tierras y su país están condenados irremediablemente al infortunio:

¿Por qué, Alejandro, esta tierra atrae la ira de Dios? ¿Por qué la han llamado tierra de Gracias, cuando las desgracias no nos dan tregua? ¿Cómo se le ocurrió a Colón pensar que había llegado al Paraíso? ¿Dónde está ese Dorado que han pintado unos cronistas necios? Si cuando no es una cosa es la otra, si por casualidad nos mandan con una mano a un gobernador decente, con la otra nos acuñan a la Compañía Guipuzcoana para que nos deje exangües, cuando no caen aguaceros que pierden las cosechas, tiembla y se vienen abajo las casas, y si dejan de asolarnos los piratas, no bombardean los ingleses, ... y cuando todo aparece estar en calma, se alzan unos negros y queman una hacienda. (29-30)

El fatalismo que marca tanto el origen de la nación como el litigio por las tierras cacaoteras se desarrolla en la primera parte del texto. El relato minucioso -en torno a la burocracia colonial, las complejas relaciones con la metrópolis, del sistema de jerarquías sociales y raciales- se erige como antecedente ineluctable de muchos de los exabruptos jurídicos y políticos narrados en la segunda (1846-1935) y tercera parte (1935-1985) de la novela. A través de la exploración afanosa de sus recuerdos, doña Inés se plantea la historia de sus tierras y del país como espacios de dominaciones, violaciones y exterminios (Calles 95; Franco 67). ${ }^{8}$ Sin embargo, como hemos visto anteriormente, la

8 Este afán por recuperar una memoria perdida podemos reconocerlo no sólo en otras obras de Ana Teresa Torres, sino también en varias muestras de la narrativa venezolana de la década de los noventa, como Reino de Buría de Miguel Arroyo (1993), Diario del Enano de Eduardo Liendo (1995), Salomón de Gustavo Luis Carrera (1993) y Viejo de Adriano González León (1995). Sobre este corpus Aura Marina Boadas advierte que: "La visión de los hechos, no es la de la oficialidad, es la de narradores que podríamos catalogar como subalternos o marginales, ... aquellos de los que siempre se habla, pero que nunca han podido tomar la palabra y que han sido relegados a causa de su condición social, su origen étnico, su género, su edad, su irreverencia ante el sistema" (44).

Revista Iberoamericana, Vol. LXXIX, Núms. 244-245, Julio-Diciembre 2013, 1103-112 ISSN 0034-9631 (Impreso) ISSN 2154-4794 (Electrónico) 
narradora representa a los grupos tradicionalmente marginados como los causantes de la fractura de un añorado orden colonial. En esta revisión tan irónica como emotiva de la historia familiar, resultan particularmente significativos los vínculos entre mantuanos y afrodescendientes. Desde el párrafo inicial de la novela se expone claramente la relación de superioridad que mantiene doña Inés con las esclavas de su hacienda:

Mi vida fue atravesar mañanas lentas, días largos que el tiempo recorría despacio, vigilar el trabajo de las esclavas, verlas barrer las lajas de los patios, dar lustre a las baldosas y azulejos que hice traer de Andalucía ... o darme una vuelta por la cocina para probar la sopa ... [Y] al acudir a la hora señalada las esclavas con las mantillas en el cesto, despedirnos hasta muy pronto o hasta el domingo en Catedral, donde nos encontrábamos, las mantuanas, vestidas de negro y cubiertas por un manto, en señal de nuestro privilegio, escoltadas por dos esclavas, una para espantar a los mendigos y otra para extender la alfombrilla en los secos ladrillos de la iglesia. (11)

La relación de la narradora con las esclavas se limitaba, pues, a la supervisión del trabajo doméstico y a la imposición de prácticas cristianas, como lo hacía al reunir diariamente a los esclavos y sus hijos, junto a la familia de los amos, para rezar el santo rosario (11). A excepción de los casos que a continuación se analizan, los esclavos y esclavas que trabajan en la casa y en la hacienda son personajes anónimos y poco relevantes en la historia.

Como consecuencia de la naturaleza unívoca y monológica de la narración, el resto de los personajes no alcanzan a exponer su versión de los hechos. Esto, desde luego, incluiría a los personajes afrodescendientes. Sin embargo, desde un locus de enunciación moralmente ambiguo, la narradora se vale de su representación del Otro, en tanto que opuesto necesario, con el propósito de legitimar el lugar que ocupó -y que inútilmente intenta recuperar-en la sociedad colonial. La mayoría de los personajes negros de Doña Inés contra el olvido se limitan a desempeñar una función utilitaria en la vida de los mantuanos. Sin embargo, en la primera parte de la novela destacan en este grupo los personajes del paje liberto Juan del Rosario y de la esclava Daría. El primero de ellos constituye un elemento capital en la obsesión de doña Inés por recuperar sus tierras. Como he mencionado anteriormente, Juan del Rosario es el hijo ilegítimo de Alejandro, esposo de doña Inés, y de una esclava de la hacienda. La descripción de este personaje secundario está marcada por la rivalidad y animadversión que siente la narradora por a amante de su marido. A título ilustrativo, me gustaría recoger el momento cuando la mantuana, al dirigirse a Alejandro, deja al descubierto sus inseguridades ante el vínculo emocional y sexual que sostiene el patriarca con su barragana:

Tengo muy presente a la madre de este niño que me obligaste a tener de paje, la veo, como si fuera ahora, ponerte las cataplasmas, servirte las tisanas y sobarte la descompostur de la mano que te torciste al caer del caballo, la oigo rezar por las noches el Padre

17. Revista Iberoamericana, Vol. LXXIX, Núms. 244-245, Julio-Diciembre 2013, 1103-1121 ISSN 0034-9631 (Impreso) ISSN 2154-4794 (Electrónico)
Nuestro al revés para invocar a Mandinga, espío sus pasos en la cocina mientras las otras negras duermen, y dice allí ensalmes cuando prepara los bebedizos para amarrar voluntades. ¿Crees tú que no distinguía su voz cuando conversaba con las brujas? (14)

Para doña Inés, la atracción que siente Alejandro por la esclava sólo puede ser el producto de sus prácticas paganas, invocaciones diabólicas y, sobre todo, de su moral alivianada. Insiste la narradora en evocar la afición de aquella mujer por los carnavales y fiestas del pueblo, aunque tales jolgorios fueran condenados por el obispo Escalona: "Se burlaba bien de las recomendaciones del comisario del Santo Oficio que muy claro habían vetado las comedias y pandorgas, los fandangos y danzas, tanto en los despoblados como en los arrabales, ... donde todo eran solicitaciones deshonestas, adulterios, incestos, fornicaciones, desafíos, quimeras y otras consecuencias perniciosas" (14-15). Tal como lo presenta doña Inés, la rivalidad entre ambas es desigual, pues, aunque la mantuana ostente una conducta irreprochable y goce de reconocimiento social, la esclava recurre a fuerzas malignas y a prácticas sexuales desprejuiciadas para despertar la lujuria de Alejandro. Desde esta perspectiva, tanto la narradora como su esposo habrían sido víctimas de la esclava.

Con todo, en doña Inés se confunden los sentimientos de amor y rechazo por Juan del Rosario. Ella lo vio nacer, lo protegió de una muerte prematura, impidió que su marido lo vendiera, lo vio jugar con sus hijos, lo hizo su paje y -desafiando la voluntad de don Alejandro- lo manumitió. Según doña Inés, Juan del Rosario no retribuyó consecuentemente aquellas demostraciones de afecto y generosidad. ${ }^{9} \mathrm{Al}$ reclamar las tierras que le legara don Alejandro, el liberto habría traicionado a quien fuera su ama:

¡Y así me pagaste, negro alzado! Diciendo que las tierras eran tuyas. ¿Tuyas de qué y de cuándo? No tienes nada. ... Nada que no provenga de mi generosidad y mi poder negro andrajoso, desnudo te cargué en mis brazos el día que naciste y hubiera podido ahogarte en el pozo de mi casa, sin remordimiento ni castigo; hasta me debes la madre, que negra más floja y falta de respeto no tuve nunca y más de una vez quise venderla y salir de ella, y no lo hice por lástima de ti, por dejarte huérfano... ¿pero que te ufanaras de tu padre, que le gritaras al mundo que esas tierras eran tuyas y que él te las daba porque esa era tu herencia?, eso, Juan del Rosario, no lo pude soportar. ¿Dueño de mi patrimonio? ... Así me consagraré a querellarme contigo. (20-21, el énfasis es mío)

El pasaje anterior sugiere el origen de la sed de venganza que delinea un litigio de casi tres siglos. En las numerosas exposiciones de los motivos que la llevaron rastrear el destino de las tierras de Curiepe, el lector puede percibir que, más allá de su

Los reclamos que profiere doña Inés en contra de Juan del Rosario se apoyan en la deslealtad e ingratitud del antiguo esclavo. En estos ataques, la matrona apunta a la condición racial de su enemigo con el propósito de destacar el grado de transgresión del sujeto subalterno.

Revista Iberoamericana, Vol. LXXIX, Núms. 244-245, Julio-Diciembre 2013, 1103-1121 ISSN 0034-9631 (Impreso) ISSN 2154-4794 (Electrónico) 
valor material, prevalecen un afán de revanchismo y un orgullo que le impiden tolerar que un mulato -hijo bastardo de una esclava, sirviente y desclasado- haya podido arrebatarle, no sólo sus pertenencias, sino también el encumbrado lugar que ocupara en la sociedad colonial.

En el enfrentamiento que sostiene doña Inés con Juan del Rosario, descuellan dos temores capitales en el círculo de los blancos criollos en el periodo colonial. El primero de ellos apunta al recelo de los hacendados de ser víctimas de conspiraciones y levantamiento de esclavos que atenten contra la bonanza económica, el poder político y social e incluso la propia vida de los mantuanos. En segunda instancia, doña Inés rechaza el blanqueamiento legal de los pardos (por medio de la compra de papeles de blanco), ${ }^{10}$ una medida que les aseguraría el ascenso social. Al situarse en un espacio supratemporal y espectral, la narradora es capaz de conectar una larga serie de episodios de la historia patria con el propósito de sustentar y comprobar sus temores. Como se puede apreciar en la tercera parte de la novela, algunos personajes descendientes de los esclavos de Curiepe alcanzan importantes espacios de poder aprovechando coyunturas como las guerras del XID, las reformas agrarias y los movimientos políticos de raigambre populista e integracionista. Tal es el caso de la militancia del personaje de Ernestino Tovar ${ }^{11}$ en el partido Acción Democrática.

En el análisis del tratamiento de los personajes de esclavos en Doña Inés contra el olvido es preciso dedicar especial atención a las intersecciones de género, clase y raza. Al respecto se puede trazar cierta continuidad en la representación de estereotipos que surgen en la sociedad colonial y que podemos rastrear hasta el último periodo histórico abordado en el texto (finales del siglo Xx). En el breve inventario de caracterizaciones de esclavas en la narrativa venezolana de corte histórico, destacan sus representaciones como servicio doméstico, figuras maternales y protectoras para los hijos de sus amos, víctimas del sometimiento sexual por parte de sus amos blancos, portadoras de sensualidades voluptuosas y sexualidades desinhibidas y, entre otras, como las encargadas de perpetuar el sistema de creencias y prácticas culturales ancestrales.

Una lectura epidérmica de Doña Inés contra el olvido sugeriría su afiliación a las representaciones tradicionales de sujetos femeninos afrodescendientes, sobre todo si se toma en cuenta que los personajes de esclavas de esta novela se delinean en constante oposición al de las mujeres blancas y, más particularmente, se articulan como el reflejo

\footnotetext{
10 En el periodo colonial, los papeles de blanco eran instrumentos legales que acreditaban la condición blanca de los criollos.

${ }^{11}$ Poco se dice de los orígenes de Ernestino Tovar, un personaje que aparece en la tercera parte de la novela. Quien fuera conocido como "el negrito de la lata de agua" (204) se convertiría en 1945 en el fundador del primer núcleo del partido Acción Democrática en los valles de Barlovento y en el hombre más respetado
} de su pueblo (204).

172 Revista Iberoamericana, Vol. LXXIX, Núms. 244-245, Julio-Diciembre 2013, 1103-1121 ISSN 0034-9631 (Impreso) inverso del personaje de la narradora. ${ }^{12}$ No obstante, en un segundo nivel de enunciación, la novela de Torres podría ser leída como una reacción a textos canónicos que abrazan discursos nacionalistas de vocación integracionista, entre los que se pueden mencionar las novelas de Díaz Rodríguez, Gallegos y Úslar Pietri. En estos textos la concordia interracial se presenta como el estadio necesario para la sólida construcción de una nación moderna. La participación activa en este proyecto de modernización impone el blanqueamiento compulsivo y progresivo -tanto racial como sociocultural- de los elementos que componen la nación. En Doña Inés contra el olvido la comunión entre los diferentes grupos raciales es un proyecto postergado. Aunque su vigencia sea incontestable, la jerarquía del color también abre paso a nuevas distribuciones de poder que incluyen, entre otros aspectos, la afiliación política con el bando ganador y, por supuesto, el desplazamiento de capitales.

En este texto, la modernización trae consigo el reemplazo de un sistema económico sustentado en las plantaciones y en la mano de obra esclava por la presencia de inversiones extranjeras. En el curso de casi tres siglos, los antiguos terrenos cacaoteros de doña Inés pasaron de mano en mano: fueron expropiados para la construcción de un ferrocarril, posteriormente se convirtieron en sembradíos de cocoteros, hasta finalmente ser un codiciado lugar para la construcción de un emporio turístico (198). En el tránsito hacia una sociedad moderna, el sistema de alianzas económicas y sociales sufre numerosas transformaciones; a pesar de ello, la narradora constata amargamente la persistencia del clientelismo y rentismo a lo largo de los diferentes procesos políticos que recoge en su relato. En este escenario, los grupos subalternos representados en la novela -particularmente, los campesinos y afrodescendientes- permanecen relegados en la repartición de "dadivas estatales", un fenómeno que sin duda acentuaría la marginalidad y pobreza de estos colectivos.

Mujeres AFrodesCENDIENTES y ORDEN SOCIAL EN DOÑA INÉS CONTRA EL OLVIDO

En su acercamiento paródico a las narrativas históricas del XIX y principios del Xx, Torres recicla aparatos retóricos a través de los cuales el sujeto femenino afrodescendiente permanece subordinado a las acciones de personajes de mujeres y hombres blancos y, también, a los de hombres negros y mestizos. En estos discursos homogeneizantes, los

\footnotetext{
12 En su análisis de las configuraciones genéricas de las esclavas en prácticas literarias estadounidenses, Venetria K. Patton advierte que estas mujeres fueron relegadas al papel de procreadoras, mientras que se les negaba el desempeño de los roles de género tradicionalmente asociados a sus congéneres blancas: "They were seen as mere chattel, not women however, this is itself was not sufficient to degender the slaves. Although the slave masters may not have acknowledged gender difference, female slaves were able to create their own sense of gender identity. Yet the institution of slavery necessitated that their conception of gender be different from that of their white witness" (xvi)

Revista Iberoamericana, Vol. LXXIX, Núms. 244-245, Julio-Diciembre 2013, 1103-1121 ISSN 0034-9631 (Impreso) $\quad$ ISSN 2154-4794 (Electrónico)
} 
personajes de mujeres afrodescendientes se articulan, no a partir de rasgos individuales y distintivos, sino respondiendo a los mencionados arquetipos de la madre, amante y sirvienta. Tales son los casos de los personajes de negras -todos ellos secundarios-que encontramos en Doña Inés contra el olvido. A pesar de las constantes referencias al personal doméstico de su casa grande, en rarísimas ocasiones doña Inés hace alusión al nombre de sus esclavas. Tan anónimas como intercambiables, aquellas mujeres funcionaban exclusivamente como objetos de ostentación, encumbrando así la holgura económica y rango social de las familias mantuanas. Justamente por ello, cobran relevancia en la recomposición de la historia de los Villegas y Solórzano los pocos personajes de negras que logran escapar del anonimato.

La primera de ellas, a quien hiciera referencia anteriormente, es la madre de Juan del Rosario. Este personaje sirve como elemento de ignición de un discurso moralizante a través del cual doña Inés expone sus prejuicios racistas y, por otra parte, es el objeto de las inseguridades más viscerales de doña Inés ante las armas de seducción de quien fuera la amante de su esposo. Por medio de este personaje, la narradora introduce una de las pocas alusiones al modo de vida de los negros de la hacienda. Sin embargo, las anécdotas que doña Inés comparte con el lector-por ejemplo, las alusivas a las prácticas religiosas, las actividades de esparcimiento y las relaciones que sostienen los esclavos y esclavas entre sí- pasan por el tamiz de su desconocimiento y aparente desinterés por quienes tan poco tenían en común con ella. Por tanto, poco sorprendería que la narradora se exima de tomar partido a propósito del tratamiento inhumano de la empresa esclavista. Una posible interpretación de esta postura sugeriría que para doña Inés la explotación física y sexual son prácticas indisociables de la condición esclava. No obstante, la mantuana sí reprueba tajantemente los cuidados y atenciones que -a su juicio- ofreciera voluntariamente la madre de Juan del Rosario a don Alejandro. Este rechazo se sustentaría en el abandono de la esclava de su condición de objeto para asumir un papel activo en una relación que contraviene las normas sociales, morales y religiosas de la época. En esta representación del enfrentamiento entre ambas mujeres, Torres echa mano al concepto de honor como instrumento de diferenciación racial y social en la sociedad colonial. Como lo apunta María Valdivia: "El honor establecerá pautas que diferenciarán a estas mujeres a partir de lo permitido y lo no permitido para los cuerpos femeninos de la época... En el caso de las mujeres, el honor se basaba en su conducta y honor sexual" (258). En este sentido, doña Inés se sabría portadora de una estirpe de mujeres honorables y, por tanto, responsable de preservar el decoro propio y el de la familia. Con todo, los amoríos de don Alejandro con su esclava llevan a la narradora a cuestionarse su capacidad de proveer el placer carnal que tanto parece reclamar su marido:

Me desagradaba encontrar en tu cuerpo el sudor de las negras. ... ¿Eras tú o era el demonio quien le abría a la madre de Juan del Rosario el cerrojo que yo tan celosamente

Revista Iberoamericana, Vol. LXXIX, Núms. 244-245, Julio-Diciembre 2013, 1103-112 ISSN 0034-9631 (Impreso) ISSN 2154-4794 (Electrónico) guardaba? Pero finalmente, poco importa, si confiesas que tambien en mí, bajo las sábanas de hilo, dejaste con ternura tu simiente entre mis piernas. ¿O era mentira? ¿Sólo amaste en mí la pureza del linaje, la cercanía de parentesco y la continuidad de las costumbres? Dime que no, no seas mezquino, dime que también mi cuerpo fue pasto de tu codicia y que yo también te tenté a la sombra del guayabo. (24)

Sólo a través de su enfrentamiento con esta esclava, se permite doña Inés expresarse como sujeto amante, una faceta de su vida que tuvo que relegar para dar lugar a otras tareas marcadas por los compromisos en el hogar, en su entorno social y, por supuesto, en su defensa del patrimonio familiar.

En el marco del anonimato que caracteriza a las esclavas que rodean a doña Inés, destaca la figura transgresora de la joven Daría que encontramos en el capítulo dedicado a la gesta independentista, "Crónica de guerra (1810-1814)". En este episodio, la narradora relata la fuga de todos los esclavos de la hacienda, a excepción de los ancianos, discapacitados, mujeres y niños (53). Cuenta la mantuana que en la noche del Jueves Santo de 1812 un castigo divino por el desacato a la autoridad del Rey terminó de desolar aquella tierra de nadie. El gran terremoto tomaría por sorpresa la hacienda La Trinidad y a los pocos habitantes que en ella quedaban. En tal trance se encontraban quienes entonces eran los últimos sobrevivientes de la dinastía Villegas y Solórzano. Aquella noche, Isabel, viuda del nieto de doña Inés, daría a luz a una niña del mismo nombre, quien crecería bajo los atentos cuidados de la esclava Daría.

La primera referencia que tenemos de este personaje nos habla de su interés por la escritura Daría observaba con atención a doña Isabel, cuando esta - a falta de escuelase encargaba de enseñar a sus hijos a escribir:

La niña llora y la negra la acerca a su seno y le dice muchas palabras que no sabe escribir: "Doña Isabel, dígame, su merced, cómo digo yo, azuquita, pajarito, niña juiciosa, la negra te levanta, la negra te acuesta. Escríbame, su merced, cómo son las palabras que digo yo". Isabel le coge la mano y le hace escribir su nombre. "No creas tú, Daría, que todas las blancas escriben, escribir no es misión de las mujeres. Yo te prometo que cuando termine la guerra, te enseñaré". (56)

El intercambio que sostienen doña Isabel y Daría sugiere la existencia de lazos de solidaridad aupados por la situación de ambas (y sus respectivos grados de subalternidad) en una sociedad que cercenaba la búsqueda de la superación personal de las mujeres para favorecer, en cambio, su total dedicación a los cuidados del hogar y de la familia. Para Daría la palabra escrita abre la posibilidad a una nueva vía de comunicación con la niña Isabel y con el mundo exterior. Debido a su condición de esclava, el aprendizaje de la lectura y escritura depende exclusivamente de la voluntad de su ama.

Aunque la matriarca describe a su nieta política como una hacendada patriota, el texto no ofrece datos acerca de los posibles afanes antiesclavistas de doña Isabel. No

Revista Iberoamericana, Vol. LXXIX, Núms. 244-245, Julio-Diciembre 2013, 1103-1121 ISSN 0034-9631 (Impreso) ISSN 2154-4794 (Electrónico) 
obstante, sí se hace referencia a cierta cercanía entre esta y la nodriza de sus hijos. La unión entre ambas se afianza en la absoluta lealtad de Daría y también en las penurias a las que ambas deben hacer frente con el propósito de salvaguardar a la familia de doña Isabel. Es esta, sin duda, la relación más estrecha entre personajes blancos y afrodescendientes que podamos encontrar en el texto de Torres y, desde luego, muy distanciada de la inquebrantable jerarquía que rige las relaciones entre doña Inés y su servidumbre. Ha corrido un siglo desde el inicio de la historia (1715) y la pugna que genera el proyecto de construcción nacional acarrea una reconsideración de las alianzas entre grupos. En el caso que ocupa nuestra atención, Daría y doña Isabel se saben vulnerables y a expensas del turbulento clima político y bélico de la época. El recién descubierto vínculo supone, por una parte, una tabla de salvación para ambas y, por la otra, delinea una grieta en la jerarquía social y racial a través de la cual surge el afecto que estas mujeres sienten por los hijos que una parió y la otra amamantó. Esta relación también evoca la nostalgia por un pasado colonial todavía muy reciente $\mathrm{y}$, sobre todo, por una red de relaciones entre blancos y negros que determinaba el funcionamiento de la economía de plantación y de la vida cotidiana de haciendas como La Trinidad. Si el patrimonio material de doña Isabel había sucumbido como consecuencia de las guerras y el terremoto, su única posibilidad de resistir y sobreponerse al descalabro de la supremacía mantuana era sacrificar el espacio íntimo en favor de la empresa independentista. Así lo hace doña Isabel al sumarse, junto a sus hijos y Daría, a una peregrinación de más de veinte mil personas que siguieron a Simón Bolívar hasta Barcelona, en el oriente venezolano.

Mientras que el resto de los personajes de esclavos son caracterizados como víctimas, resentidos o arribistas, la esclava Daría protagoniza -en el marco de esta travesía- la acción de mayor carga de heroicidad en la novela. En un gesto digno de la tradición romántica, la esclava Daría se enfrenta a las fuerzas del general José Tomás Boves que logran interceptar la caravana en la que se desplazaba junto a doña Isabel y los niños. Ceferino, un negro armado con un machete y con la bragueta del pantalón abierta, arroja a doña Isabel al suelo. Desesperada y en espera de su muerte, doña Isabel es incapaz de reconocer la voz de su esclava que intercede ante aquel hombre. Daría le ruega a Ceferino que la reconozca y que, por el recuerdo de una infancia compartida, le perdone la vida a su ama. Así lo hace.

El encuentro con Ceferino marca un punto de inflexión en la caracterización del personaje de Daría. Este le dice que sólo abandonando a doña Isabel y los niños podrían escapar, regresar a Curiepe y salvar su vida. Con el propósito de persuadir a Daría, Ceferino evoca los abusos que han debido soportar los esclavos. Sin embargo, Daría no está preparada para tomar una decisión ni siquiera para salvar su vida: “[E]n veinte años no ha dicho nunca: yo quiero, yo deseo, yo propongo. En veinte años nadie le ha dicho nunca: qué quieres, qué propones, adónde vas" (66). Daría es consciente de que ISSN 0034-9631 (Impreso) ISSN 2154-4794 (Electrónico) su huida habría traído como consecuencia una muerte a latigazos (67). A la manera de un contrapunto se entretejen la voz de Ceferino -recordándole a Daría que es una mujer fuerte- y la voz de la narradora-que afirma que su condición de negra iletrada le impide entender la justicia de su ama (67). En un arranque de valentía, Daría se lanza desde la caravana con la niña Isabel en brazos, abandonando al resto de los miembros de la familia, a quienes les espera la muerte. Al infringir la ley de los blancos, Daría también salva a la última de los descendientes de doña Inés. Hasta este momento en la historia, las acciones de los esclavos y libertos de la hacienda La Trinidad respondían exclusivamente a la voluntad de sus amos. La fuga de Daría con la niña Isabel fractura esta dinámica de sumisión y dependencia con el sujeto blanco. El futuro del clan familiar y de su patrimonio responde, entonces, a las decisiones de la fugitiva. Sin embargo, Daría no hace uso de su libertad, aún ilegítima, para su propio provecho, sino que la pone al servicio de las tierras de sus antiguos manos. Regresa así a la hacienda para trabajar junto a su hermana, Juana Solórzano, y el marido de esta, Julián Cayetano en la reactivación de la siembra de cacao.

Entre el periodo de doña Inés y el de la niña Isabel, su bisnieta, se establece cierta continuidad delineada por las promesas incumplidas que hicieran los amos blancos (don Alejandro y don Francisco) a sus respectivos mayordomos negros: Juan del Rosario, en el siglo XVIII, y Julián Cayetano, en el siglo XIx. La promesa en cuestión hace referencia a la repartición de tierras a los descendientes entre los antiguos esclavos. Para denunciar tales prácticas e ilustrar la circularidad de la historia nacional e íntima, la narradora presenta una arqueología de procesos políticos y eventos familiares que se han apoyado en esfuerzos populistas inconclusos:

Porque esta tierra, Alejandro, ha sido la invención de una promesa... Heredaste la costumbre de prometer que sembraron nuestros abuelos, otros prometidos, que vinieron a llenarse de gloria y de oro y encontraron una tierra malojera y endiablada. Durante la guerra esto fue una piñata de promesas, y después no hubo quien no se sintiera merecedor de alguna y viniera a recogerla entre los escombros, y iqué fue lo que hallaron? Más promesas. (91)

Para doña Inés, los gestos aparentemente dadivosos de su marido, su nieto Francisco y su biznieta Isabel -quien compra la libertad de Daría, su salvadora- erosionan el patrimonio familiar, al tiempo que acortan las barreras sociales y económicas que separan a los suyos (los blancos mantuanos) de los otros (los afrodescendientes).

Si para la narradora, esta es la historia del litigio por sus tierras, en el paso hacia la modernidad se puede reconocer otra historia: la del desencanto ante la incapacidad de resguardar el orden (mantuano, blanco, cristiano y burgués) en el espacio íntimo. En consecuencia, el surgimiento de una nueva nación imprime un ataque a la esfera familiar. El desplazamiento de ciertas subjetividades subalternas en la escala social 
encuentra su réplica en la historia de las tierras de la familia Villegas y Solórzano. Uno de los personajes que mejor ilustra este proceso es el de Domingo Sánchez, un afrodescendiente nieto de Juana Solórzano y Julián Cayetano, que encontramos en la última parte de la novela dedicada al siglo Xx.

Su militancia en el partido Acción Democrática y su gestión como ministro -a todas luces corrupto- le permiten acumular en poco tiempo una cuantiosa fortuna. Así, Domingo Sánchez simboliza uno de los grandes temores coloniales que acosan a doña Inés a lo largo de su historia. Para la mantuana, este personaje -debido a su condición racial y origen campesino- usurpa un lugar que anteriormente había sido asegurado por la supremacía mantuana. Como si tal transgresión no fuera suficiente, Sánchez corteja y se casa con Belén, la cuadrinieta de doña Inés. Paradójicamente, el producto del mestizaje como metáfora de la nueva nación no tiene lugar, pues Belén y Domingo no logran procrear.

La comunión simbólica entre el mundo blanco de los amos y el mestizo de los sirvientes se materializa en el pacto ilegítimo entre Francisco Villaverde, chozno de doña Inés, y José Tomás (nieto de una antigua sirvienta de Belén). El acuerdo requiere que una de las partes ceda sus derechos a la otra. Mientras Francisco reclama aquello que desde la época colonial había pertenecido a su familia y que había sido expropiado en 1884, Por su parte, José Tomás exige que aquellas tierras pertenezcan a la comunidad de afrodescendientes que durante tantos años las había explotado. En este proceso de negociación prevalecen los intereses de los antiguos amos del valle. Si bien asistimos a la puesta en escena de un encuentro entre bandos hasta entonces irreconciliables, tal gesto denunciaría una maniobra de reordenamiento del poder que privilegia el elemento tradicionalmente dominante (la burguesía mantuana y la pureza de linaje) sobre el subalterno (campesinos y mestizos).

Como espectadora del curso de la historia en los últimos tres siglos, doña Inés cuestiona la hegemonía patriarcal, el caudillismo y, entre otras cosas, la irrupción de regímenes populistas. Sin embargo, hay que recordar que para la narradora el trance abolicionista fue un ardid tramado en la efervescencia del proceso independentista para atacar a la élite mantuana. El relato de doña Inés respondería, pues, a la tradición narrativa de los amos, a través de la cual se pretendía suplantar metafóricamente las historias de quienes estuvieron bajo su mando (Handley 150). Para lograr este cometido, advierte Toni Morrison que: "The master narrative could make any number of adjustments to keep itself intact” (4). Apoyada en esta empresa, doña Inés vertebraría, por una parte la desacralización y, por la otra, la arqueología contrafundacional del descalabro de una comunidad cimentada en la violencia.

Desde esta perspectiva, la lectura de Doña Inés contra el olvido plantea un cuestionamiento de la tradición literaria dominante sobre el periodo colonial y la empresa esclavista y un ataque a los discursos etnocéntricos que han predominado en el tratamiento literario de las tensiones raciales en el contexto venezolano. ${ }^{13}$ Por medio del recurso de la parodia de la historiografía oficial, esta visión mantuana sobre el sujeto esclavizado revelaría las escisiones de los discursos nacionalistas afincados en el mito de la convivencia armoniosa de los diferentes grupos raciales y sociales, denunciando, en consecuencia, el predominio del blanqueamiento estético y temático en las narrativas venezolanas sobre la historia patria. Finalmente, es necesario advertir que, si bien la retórica nacional oficial se ha empeñado en definir la sociedad venezolana como "café con leche" y mestiza, ${ }^{14}$ uno de los rasgos predominantes de su literatura es el predominio de la blancura cultural, así como la escasez de voces periféricas que disloquen la preeminencia de subjetividades blancas, urbanas, cosmopolitas y burguesas en el panorama literario actual. En la proliferación de narrativas históricas de las dos últimas décadas, no deja de llamar la atención la ausencia de acercamientos alternativos al pasado esclavista. Desde luego, Doña Inés contra el olvido sugiere un paso a favor de la subversión de la representación tradicional de las relaciones de poder (raciales, sociales, religiosas, sexuales y, por ejemplo, de género) en la narrativa venezolana contemporánea.

\section{OBRAS CITADAS}

Arroyo, Miguel. El reino de Buría. Caracas: Monte Ávila Editores, 1993.

Blanco, Eduardo. Venezuela heroica. Caracas: Imprenta Sanz, 1881.

Boadas, Aura Marina. "Novelística venezolana de los noventa: Una relectura de la identidad". Voz y escritura 10 (2000): 43-57.

Bruña Bragado, María José. "Novelar la historia desde los márgenes: Ana Teresa Torres". Pandora: revue d'études hispaniques 5 (2005): 191-204.

Burgos Cantor, Roberto. La ceiba de la memoria. Bogotá: Planeta, 2007.

Carrera, Gustavo Luis. Salomón. Caracas: Monte Ávila Editores, 1993.

Certeau, Michel de. "Histoire et structure". Recherches et Débats 68 (1970): 165-195. Díaz Rodríguez, Manuel. Peregrina o El pozo encantado. 1922. Caracas, Venezuela: Monte Ávila Editores, 1986.

\footnotetext{
En la reescritura posmoderna del pasado esclavista, Doña Inés contra el olvido destaca en el conjunto de narrativas contemporáneas sobre el tema. En textos como La ceiba de la memoria (Roberto Burgos Cantor, 1987), Moi, Tituba, sorcière (Maryse Condé, 1986), Humus (Fabienne Kanor, 2006) o, por ejemplo, The Book of Night Women (Marlon James, 2009) se privilegia -en la remoración de este periodola perspectiva afrodescendiente; mientras que en la novela de Torres, la narradora recrea la sociedad esclavista desde la perspectiva de una blanca criolla victimizada por el curso de los acontecimientos históricos que desencadenaron la abolición de la esclavitud.

${ }_{14}$ Para un análisis de las relaciones entre identidad nacional, raza y clase en la sociedad venezolana, véase Winthrop R. Wright (1990).
} 
Díaz Sánchez, Ramón. Borburata. 1960. Buenos Aires: Centro Editor de América Latina, 1967.

Gallegos, Rómulo. Pobre negro. 1937. Caracas: Panapo, 2009.

González León, Adriano. Viejo. México: Santillana, 1995.

González Stephan, Beatriz. "Escritura de memorias subalternas". Texto crítico 10 (2002): 21-34.

Handley, George B. Postslavery Literatures in the Americas: Family Portraits in Black and White. Charlottesville: UP of Virginia, 2000.

Herrera Luque, Francisco. Boves, el urogallo. Caracas: Fuentes, 1972.

Los amos del valle. 1979. 5ta ed. Caracas: Pomaire, 1993.

Huyssen, Andreas. Twilight Memories: Marking Time in a Culture of Amnesia. New York: Routledge, 1995.

James, Marlon. The Book of Night Women. New York: Riverhead Books, 2009.

Juan-Navarro, Santiago. Postmodernismo ymetaficción historiográfica: Unaperspectiva interamericana. Valencia: Departament de FilologiaAnglesa iAlemanya, Universitat de València, 2002.

Kanor, Fabienne. Humus. Paris: Gallimard, 2006.

Liendo, Eduardo. Diario del Enano. Caracas: Monte Ávila Editores, 1995.

Meneses, Guillermo. Campeones. 1939. Caracas: Monte Ávila Editores, 1984. Canción de negros. Caracas: La Nación, 1934.

Morrison, Toni. Playing in the Dark: Whiteness and the Literary Imagination. New York: Vintage, 1992.

Mosca, Stefanía. La última cena. Caracas: Monte Ávila Editores, 1990.

Otero Silva, Miguel. Fiebre. Caracas: Elite, 1939.

Patton, Venetria K. Women in Chains. The Legacy of Slavery in Black Women's Fiction. Albany, NY: State University of New York Press, 2000.

Pérez Rescaniere, Gerónimo. Jabón de olor. Caracas: Monte Ávila Editores, 1973.

Pocaterra, José Rafael. Memorias de un venezolano de la decadencia. Caracas: Élite, 1936.

Ramos, Julio. Los conuqueros. Caracas: Tipografía Americana, 1936.

Rivas, Luz Marina. La novela intrahistórica. Mérida: El otro mismo, 2004.

Rojas, Marta. Santa Lujuría o Papeles de blanco. La Habana: Letras Cubanas, 1998.

Romero García, Manuel Vicente. Peonía. 1890. Caracas: Monte Ávila Editores, 1976.

Santaella Kruk, Fedosy. Rocanegras. Caracas, Venezuela: Ediciones B, 2007.

Sojo, Juan Pablo. Nochebuena negra. 1943. Caracas: El perro y la rana, 2007.

Suárez de Bianchi, María. "Una lectura posmoderna de dos novelas venezolanas Perfume de Gardenia de Laura Antillano y Doña Inés contra el olvido de Ana Teresa Torres". Mañongo 13 (1999): s/p.

Torres, Ana Teresa. Doña Inés contra el olvido. 1992. Caracas: Monte Ávila Editores, 1999.

Revista Iberoamericana, Vol. LXXIX, Núms. 244-245, Julio-Diciembre 2013, 1103-1121 ISSN 0034-9631 (Impreso) ISSN 2154-4794 (Electrónico)
Urbaneja Achelpohl, Luis Manuel. ;En este país! 1916. Caracas: Monte Ávila Editores, 1981.

Úslar Pietri, Arturo. Las lanzas coloradas y cuentos selectos. 1931. Caracas: Biblioteca Ayacucho, 1988.

Valvidia del Río, María de Fátima. "Sacudiendo el yugo de la servidumbre: mujeres afroperuanas esclavas, sexualidad y honor mancillado en la primera mitad del siglo XIX”. Estudios sobre sexualidades en América Latina. Kathya Araujo y Mercedes Prieto, eds. Quito: FLACSO, Sede Ecuador, 2008. 253-67.

Wright, Winthrop R. Café Con Leche: Race, Class, and National Image in Venezuela. Austin: U of Texas P, 1990
Revista Iberoamericana, Vol. LXXIX, Núms. 244-245, Julio-Diciembre 2013, 1103-112 ISSN 0034-9631 (Impreso) 
